\title{
Determinants of HIV/AIDS Awareness among Garments Workers in Dhaka City, Bangladesh
}

\author{
Nazrul Islam Mondal ${ }^{1}$, Rafiqul Islam ${ }^{1}$, Obaidur Rahman $^{1}$, Shafiur Rahman ${ }^{1}$, Nazrul Hoque ${ }^{2}$ \\ ${ }^{1}$ Department of Population Science and Human Resource Development, University of Rajshahi, Rajshahi, Bangladesh; ${ }^{2}$ Department \\ of Demography, Institute for Demographic and Socioeconomic Research, The University of Texas at San Antonio, One UTSA Circle, \\ San Antonio, USA.

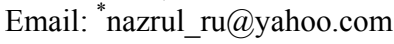

Received August 16 ${ }^{\text {th }}, 2012$; revised October 19 ${ }^{\text {th }}, 2012$; accepted October $26^{\text {th }}, 2012$

\begin{abstract}
The main purpose of this study is to find the awareness level as well as the determinants of awareness on HIV/AIDS among the garments workers in Dhaka City, Bangladesh. To do so, 200 garments workers were interviewed through a structured questionnaire using purposive sampling technique. As the statistical tools, univariate analysis was completed to figure out frequency distribution and the binary logistic regression model was used to predict the probability occurrence of the events by fitting data. The results revealed that the majority of the garments workers $(63.5 \%)$ are very young (18 - 27 years), almost all (97.5\%) are literate and most of them (57.0\%) used contraceptives. Importantly, most of the respondents $(64.0 \%)$ had not participated in any type of seminar or workshop related to HIV/AIDS, though almost all the respondents (84.5\%) know HIV is a dangerous and life threatening disease. The logistic regression model identified that respondents' education, contraceptive usage, mass media and HIV workshops have statistically significant positive effects on HIV/AIDS awareness. Various media campaigns are strongly suggested to be increased knowledge and awareness to control the spread of HIV as well as STDs among garments workers in Bangladesh.
\end{abstract}

Keywords: HIV/AIDS; STDs; Garments Workers in Bangladesh; Logistic Regression Model

\section{Introduction}

Acquired Immune Deficiency Syndrome (AIDS) is known as the killer disease caused by Human Immunodeficiency Virus (HIV). AIDS is the late clinical stage of HIV infection, a serious health condition in which a human body's defenses against some illnesses breakdown and subsequently acquire diseases which are typically not life threatening. HIV is a parasite virus that attacks the immune system's soldiers - the CD4 cells (T-cells) and makes a body susceptible to and unable to recover from other opportunistic diseases. The virus is generally transmitted through sexual contact, infected women to their unborn children, or through contaminated needles (infections) or blood. HIV/AIDS has become global health problem. Many countries around the world are experiencing an epidemic of this sexually transmitted disease (STD). The first recognized cases of AIDS occurred in the USA in June 1981 [1]. Since then the disease has increased tremendously. At the end of 2010, an estimated 34 million people were living with HIV worldwide, up $17.0 \%$ from 2001 [2]. There were 2.7 million new HIV infections in 2010, including an estimated 390,000 cases

${ }^{*}$ Corresponding author. among children, this was $15.0 \%$ less than in 2001 , and annual new HIV infections fell $21.0 \%$ between 1997 and 2010 [2]. Clearly, the number of people becoming infected with HIV is continuing to fall. The number of people dying of AIDS-related causes fell to 1.8 million in 2010 and the proportion of HIV affected women has remained stable at $50.0 \%$ globally [3].

Bangladesh is one of the few countries in the South Asia region with a low HIV prevalence. In Bangladesh, the first case of HIV/AIDS was detected in 1989 [4], and since then the number of HIV/AIDS patients have been steadily increasing. Since 2002 the number of HIV infected persons has been increased faster (Figure 1). Till December 2010, there were 2088 reported cases of HIV and 850 cases of AIDS; among these cases, 241 died [4]. However, at the end of 2008, there were only 1495 active HIV cases and 476 cases of AIDS [5]. Though this is not a large number, it is a threat for the health of the country. Bangladesh, is considered as a low prevalence country. The 9th Round National HIV Serological Surveillance, 2011 identified prevalence less than $1 \%$, but there are significant levels of risky behaviors that make Bangladesh vulnerable to HIV/AIDS. While analyzing data from the first round of national HIV Serological Surveillance 


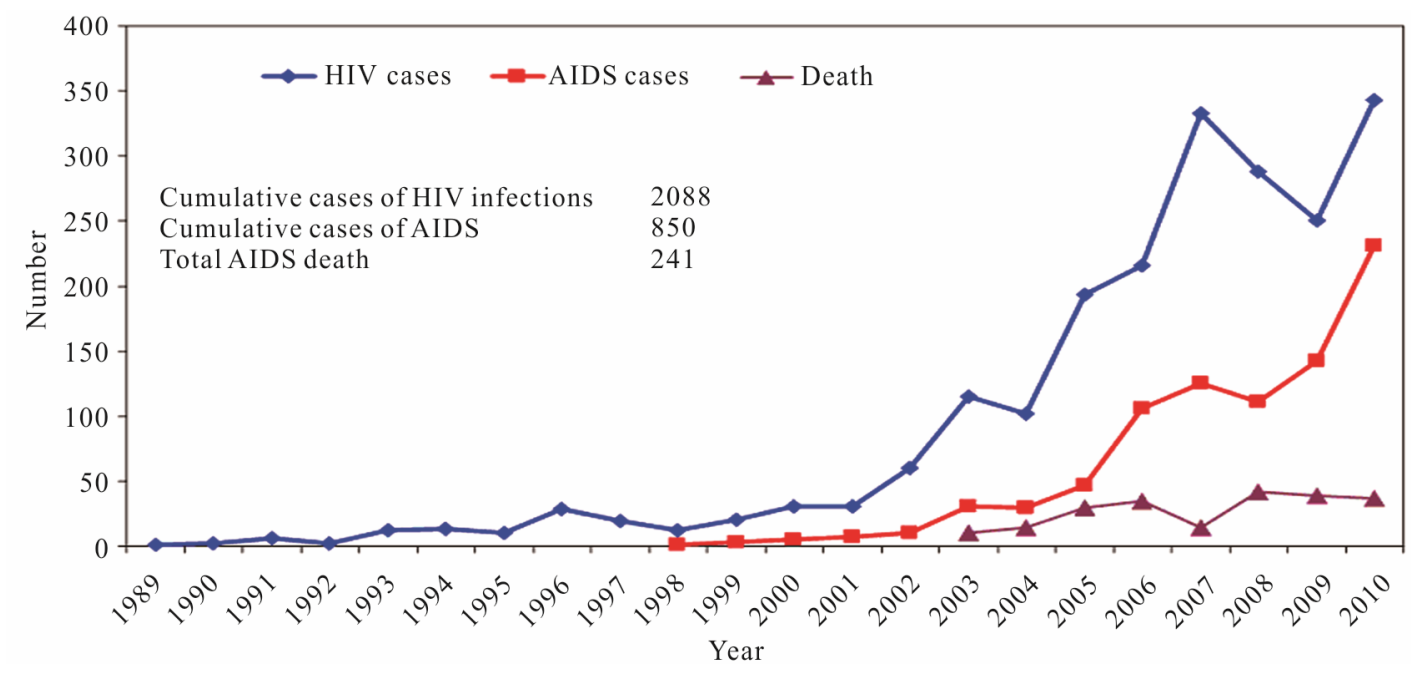

Figure 1. Reported HIV and AIDS cases and deaths in Bangladesh from 1989 to 2010. Source: [8].

conducted in 1998-1999 to the 9th round conducted in 2010-2011, HIV prevalence among most at risk population (MARP) were always found higher than that of total population (Figure 2). Although HIV prevalence among MARP have remained $<1 \%$, the trend have been increasing over the years 1998-2011 (Figure 3), especially from 1999 to 2007 (Round II to Round VII). The most vulnerable groups for HIV/AIDS in Bangladesh are: commercial sex workers (CSW), men who have sex with men (MSM), male sex worker (MSW), transgender and injecting drug users (IDU) [6]. In this regard, it has been identified that male migrants are also a high risk group for HIV [7]. The 9th Round HIV Serological Surveillance added the clients of sex workers, with the aforesaid group, including dock workers, rickshaw pullers and truckers as risky groups [8]. In Bangladesh, some other groups may also be considered as vulnerable to HIV due to their risky sexual behaviors, such as professional blood donors, garment workers, smugglers, fishermen, etc. Significantly, Bangladesh is vulnerable to an expanded HIV epidemic due to the prevalence of behavioral patterns and risk factors including a large commercial sex industry, low rate of condom use, needle-sharing among IDUs, and lack of knowledge that facilitates the rapid spread of HIV [9].

Garments workers play an important role in the economy as this sector brings in about $76 \%$ of the country's total merchandise export earnings [10]. Because of cheap labor, pressure for globalization of production based on location economies as well as the favorable treatment from developed countries, Bangladesh and some other developing countries have gradually become the global players in international trade for Ready Made Garments (RMG). In Bangladesh, garment workers constitute $40.0 \%$ of the total industrial workforce [11], and 2 million workers are employed; among them $80.0 \%$ are women. The pathetic scene for garment workers includes an average working day of about 10 hours, and they are still neglected in our Bangladesh [10]. They are paid little for their contribution, and are still deprived of their basic rights. Workers are not highly educated and inhabit lower conditions. The mass media did not focus on this group. These workers do not have enough time for any type of entertainment like reading daily newspapers, watching television (TV), participating in seminars etc. On the other hand, they may be involved with unprotected sex, needle-sharing with IDUs and taking drugs. Garment workers often leave behind their husbands/ wives in their home towns or villages, which fuel the extra marital sex. Government of Bangladesh (GoB) and other non-government-organizations (NGOs) have not identified them as a vulnerable group to HIV acquisition and transmission. Therefore, it is important to explore and identify the relationship of factors for which AIDS awareness is modified significantly in the context of Bangladesh garments workers. Thus the purposes of the present study is to find the level of awareness and to identify the determinants of awareness of HIV/AIDS regarding its prevention and control among garments workers in Bangladesh.

\section{Data and Methods}

In this study, data taken from a total of 200 (male: 100, female: 100) garments workers were interviewed during 15 May 2010 to 30 November 2010 from three companies namely "The Silver Garment (BD. Ltd.)", "Islam Garment (a Group of Industries)" and "Fahami Garment" in Dhaka City, Bangladesh. Respondents were interviewed using a standard questionnaire through purposive sampling technique. Univariate and logistic regression analysis have been used to analyze the collected data. 


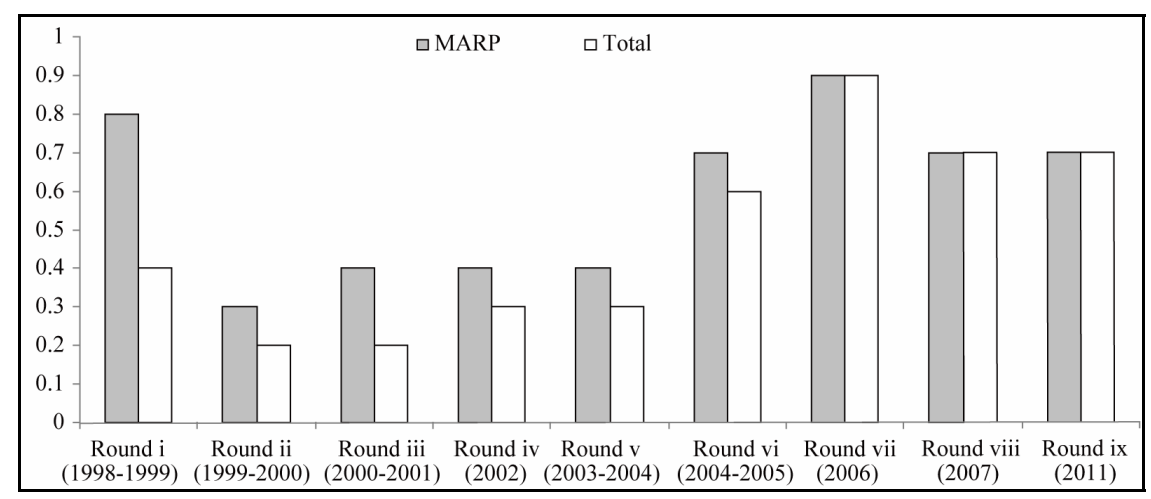

Figure 2. HIV/AIDS prevalence over the rounds of surveillance. Source: [8].

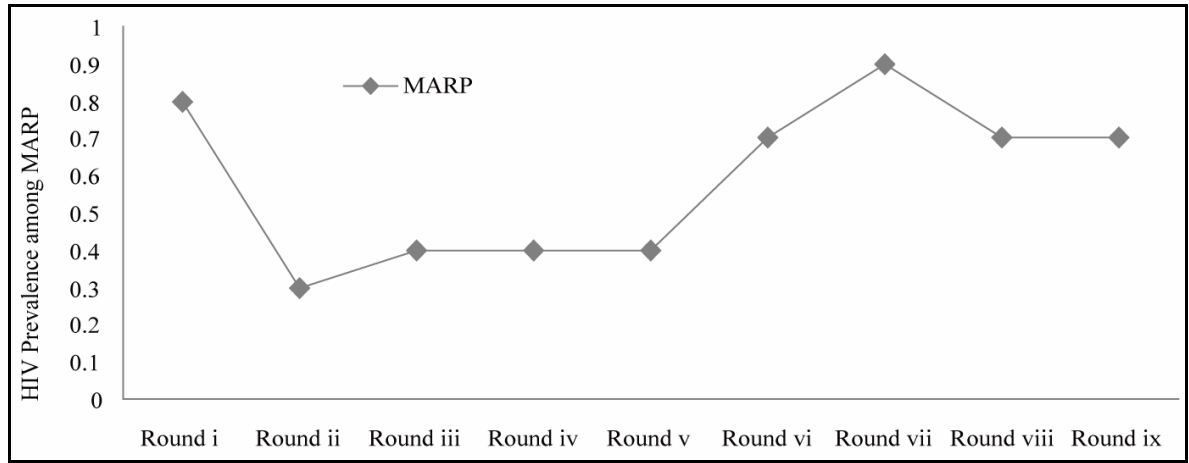

Figure 3. Trends of HIV among populations most at risk over the rounds of surveillance. Source: [8].

Initially, univariate analysis was used to explore the current situation of the respondents and finally, logistic regression analysis was completed out to identify determinants of level of awareness of HIV/AIDS among the respondents. The dependent variable used in logistic regression analysis as a dichotomous binary variable, was of the following form:

$Y=\left\{\begin{array}{l}1, \text { if the respondents have awareness about HIV/AIDS; } \\ 0, \text { otherwise. }\end{array}\right.$

The independent variables in logistic analysis were educational status, contraceptive use, aware from radio, aware from TV, participation in HIV workshop, and aware about HIV by anybody.

\section{Results}

\subsection{Background Characteristics of the Garments Workers}

Table 1 shows the socio-demographic characteristics of respondents which highlights that, more than half of the respondents $(63.5 \%)$ are young (18 - 27 years), while about, one-third $(32.5 \%)$ are between 28 - 37 years of age and the rest are in higher age groups. Almost all of the respondents are Muslim (94\%). The study also determined that, $64 \%$ respondents are married and $35 \%$ are unmarried and only $1 \%$ belong to the widowed group.
Almost all (98\%) respondents are educated, of these $22 \%$ completed primary education, $54 \%$ completed secondary education and 23\% completed higher secondary education. Among the total respondents, $75 \%$ have monthly income $<5000 \mathrm{TK}, 22 \%$ have between $5000-10000 \mathrm{TK}$ and only $4 \%$ have monthly income $>10,000 \mathrm{TK}$. Also nearly the same values are found in their monthly expenditures. Among these respondents $72 \%$ have a monthly expenditure $<5000 \mathrm{TK}, 21 \%$ have between 5000 10,000 TK and only $8 \%$ have monthly expenditure $>$ $10,000 \mathrm{TK}$.

The frequency distributions of different HIV/AIDS related variables of the respondents are presented in Table 2. The study results revealed that around half of the respondents $(43 \%)$ did not use contraceptives. Almost all of the respondents (94\%) known HIV/AIDS is contagious, about, though most of the respondents (64\%) have not participated in HIV/AIDS related seminars. On the other hand, almost all (90\%) participated in the company programs about HIV. Most of the garment workers (89\%) have knowledge about treatment of HIV and almost all (95\%) have knowledge that HIV is treatable. Most of the respondents $(85 \%)$ know that HIV is a dangerous and life threading disease and almost all of the respondents (77\%) know that HIV causes the loss disease preventing power and increases physical weakness. With help of other persons a higher percentage of respondents (90\%) are 
Table 1. Socio-demographic characteristics of respondents $(n=200)$.

\begin{tabular}{cccc}
\hline Characteristics & Frequency (\%) & Characteristics & Frequency (\%) \\
\hline Age (in years) & & Educational status & $5(2.5)$ \\
$18-27$ & $127(63.5)$ & Illiterate & $43(21.5)$ \\
$28-37$ & $65(32.5)$ & Primary & $107(53.5)$ \\
$38-47$ & $7(3.5)$ & Secondary & $45(22.5)$ \\
$\geq 48$ & $1(0.5)$ & Higher secondary & $151(75.5)$ \\
Religion & & Monthly income (TK) & $41(21.5)$ \\
Muslim & $188(94.0)$ & $<5000$ & $7(3.5)$ \\
Non Muslim & $12(6.0)$ & $5000-10,000$ & $>10,000$ \\
Sex & & Monthly expenditure (TK) & $144(72.0)$ \\
Male & $100(50.0 \%)$ & $<5000$ & $41(20.5)$ \\
Female & $100(50.0 \%)$ & $5000-10,000$ & $15(7.5)$ \\
Marital status & & $>10,000$ & \\
Married & $128(64.0)$ & & \\
Unmarried & $70(35.0)$ & $2(1.0)$ &
\end{tabular}

Note: The numbers indicated within the parenthesis represent the percentages.

Table 2. Background characteristics of HIV/AIDS related attributes $(n=200)$.

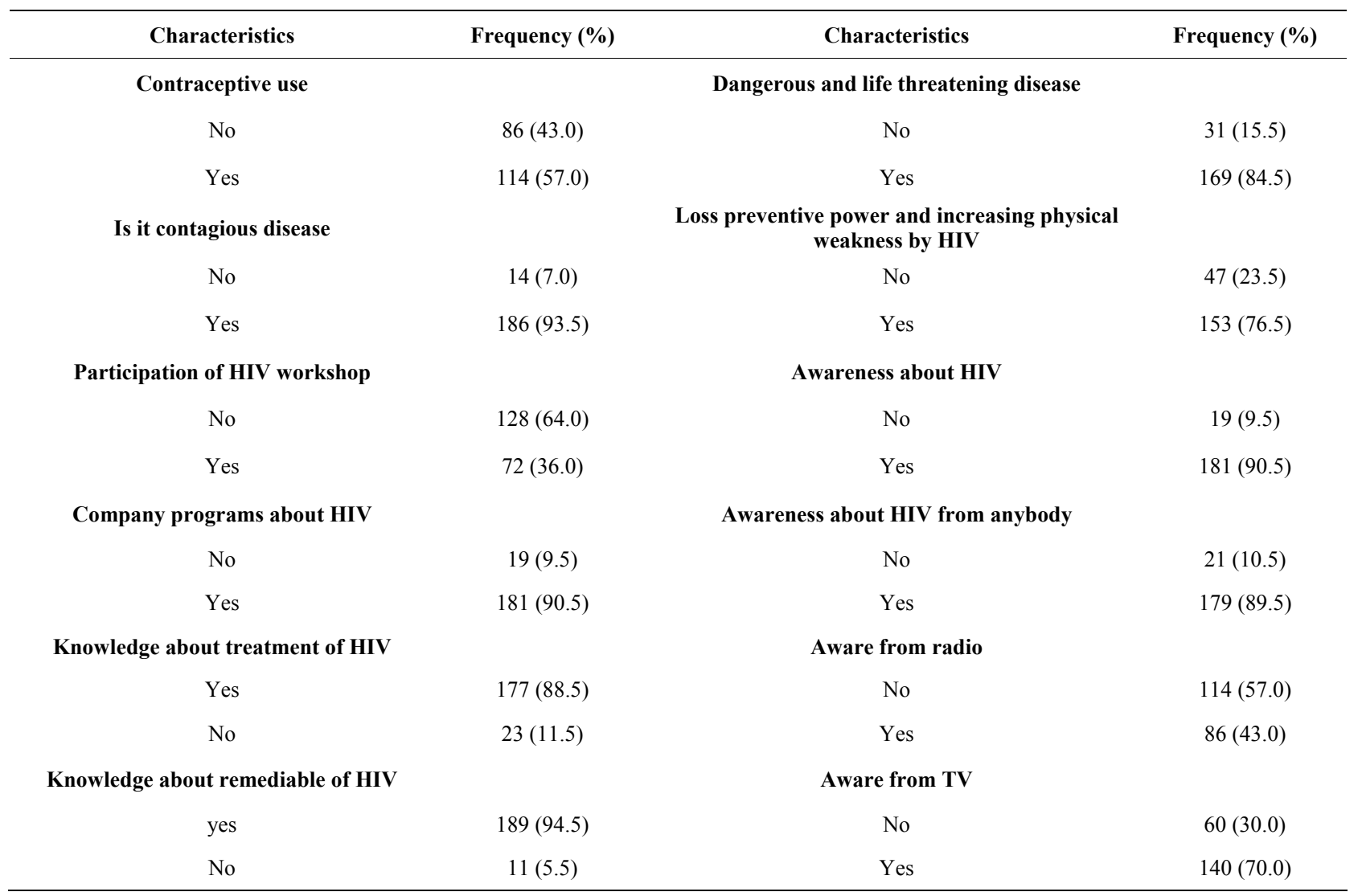

Note: The numbers indicated within the parenthesis represent the percentages. 
aware of HIV/AIDS. Regarding media as an information source, the study showed, a large proportion of respondents $(57 \%)$ became aware listening radio programs, and most of the respondents $(70 \%)$ became aware through TV programs about HIV/AIDS related issues.

\subsection{Determinants of Awareness about HIV/AIDS}

In the logistic regression model, the respondent's educational status, contraceptive use, radio program, TV program, HIV workshop, and aware about HIV by anybody have been considered as the predicator variables. All these predictor variables significantly associated with the awareness of HIV/AIDS among garments workers. The results of logistic regression analysis included regression coefficients ( $\beta$-values), $\mathrm{p}$-values and odds ratios (OR), and $95 \%$ level of confidence interval (CI) which are presented in Table 3.

The study results showed that education has a statistically positive significant effect $(\mathrm{p}<0.001)$ on awareness about HIV/AIDS. The regression coefficient is 0.56 and $\mathrm{OR}=1.75(95 \% \mathrm{CI}=1.241-2.474)$, which indicates that literate garment workers are 1.75 times more likely to have awareness about HIV/AIDS than their illiterate counterparts. In case of contraceptive use, it has a positive significant effect $(p<0.012)$ on HIV/AIDS awareness. The regression coefficient is 2.245 and $\mathrm{OR}=9.44$ $(95 \% \mathrm{CI}=1.640-66.705)$, which imply that there is a positive relationship between contraceptive use, and HIV awareness and the garments workers who use contraceptives are 9.44 times more likely to have awareness about HIV/AIDS compared to those who do not use contracep- tives. Mass-medias programs about AIDS play an important role in raising the awareness level in all sections. In case of media, the study revealed that garment workers who watch TV are 7.12 times more aware about HIV/AIDS than those who did not watch TV $(\beta=1.963$, and $\mathrm{OR}=7.12,95 \% \mathrm{CI}=1.278$ - 39.644). Thus TV programming is a strong media effect which has significant impact $(\mathrm{p}<0.025)$ in raising the awareness about HIV/ AIDS. Similarly AIDS related radio programs also have positive effects $(p<0.094)$ on awareness about HIV/ AIDS. The regression coefficient and OR for garment workers who listen to radio programs about AIDS are 1.857 and $6.41(95 \% \mathrm{CI}=0.727-56.407)$ respectively. This indicates that garment workers who listened to radio programs about AIDS are 6.41 times more likely to have awareness about AIDS than their counterparts. Participation in an HIV/AIDS workshop also has a significant positive effect $(\mathrm{p}<0.019)$ on their awareness. The regression coefficient is 2.216 and $\mathrm{OR}$ is $8.38(95 \% \mathrm{CI}=$ 1.419 - 49.489) for garment workers who participated in an HIV/AIDS workshop, which implies that garments workers who participate in workshops are 8.38 times more aware about HIV/AIDS than those who do not participate in HIV/AIDS workshops Generally, the garments workers who participate in HIV/AIDS workshop acquire a greater knowledge about HIV/AIDS and they are conscious about this disease. The study also revealed that the regression coefficient of the respondents who are aware of HIV/AIDS by anybody is 2.184 and the corresponding OR is $8.88(95 \% \mathrm{CI}=1.311-60.157)$, which implies that the respondents who are aware about HIV/AIDS by anybody has a significant impact $(\mathrm{p}<0.025)$ and is 8.88

Table 3. Determinants of the HIV/AIDS awareness of the garments workers.

\begin{tabular}{|c|c|c|c|c|c|c|}
\hline \multirow{2}{*}{ Predicators } & \multirow[b]{2}{*}{ Co-efficient of $\beta$} & \multirow[b]{2}{*}{ S.E of $\beta$} & \multirow[b]{2}{*}{ p-value } & \multirow[b]{2}{*}{ OR } & \multicolumn{2}{|c|}{$95 \% \mathrm{CI}$} \\
\hline & & & & & Lower & Upper \\
\hline \multicolumn{7}{|c|}{ Educational status } \\
\hline Illiterate (r) & - & - & - & 1.00 & & \\
\hline Literate & 0.561 & 0.176 & 0.001 & 1.75 & 1.241 & 2.474 \\
\hline \multicolumn{7}{|c|}{ Contraceptive use } \\
\hline No $(r)$ & - & - & - & 1.00 & & \\
\hline Yes & 2.245 & 0.893 & 0.012 & 9.44 & 1.640 & 66.705 \\
\hline \multicolumn{7}{|l|}{ Radio program } \\
\hline No $(\mathrm{r})$ & - & - & - & 1.00 & & \\
\hline Yes & 1.857 & 1.110 & 0.094 & 6.41 & 0.727 & 56.407 \\
\hline \multicolumn{7}{|l|}{ TV program } \\
\hline No (r) & - & - & - & 1.00 & & \\
\hline Yes & 1.963 & 0.876 & 0.025 & 7.12 & 1.278 & 39.644 \\
\hline \multicolumn{7}{|c|}{ Participation in HIV workshop } \\
\hline No $(r)$ & - & - & - & 1.00 & & \\
\hline Yes & 2.126 & 0.906 & 0.019 & 8.38 & 1.419 & 49.489 \\
\hline \multicolumn{7}{|c|}{ Aware about HIV from anybody } \\
\hline No (r) & - & - & - & 1.00 & & \\
\hline Yes & 2.184 & 0976 & 0.025 & 8.88 & 1.311 & 60.157 \\
\hline
\end{tabular}

Note: $r$ represents the reference category. 
times more likely to have awareness about HIV/AIDS than that of the respondents who are not aware about HIV/AIDS by anybody.

\section{Discussion}

HIV is not only an epidemic, today it is a global concern. The results from this study indicate a higher proportion of young aged garments workers in the respective study area. Because of poverty, high growth rate and shortage of jobs, young people are being forced to participate in any type of work for their livelihood. Most of them are not highly educated so, they cannot get a good job with better salary. Jobs in the garment sector, as a low level worker, require less educational qualifications and less experience (sometimes no experience). These workers get low salaries. The present study provides evidence of their low income $(\leq 5000$ TK monthly) and low expenditures ( $\leq 5000 \mathrm{TK}$ monthly) representing a low standard of living. Consistent with other studies [12-14] the findings indicate that education predicts the level of HIV/AIDS awareness and reiterates the importance of education for Bangladesh. The findings of this study also suggest that the respondents are not sufficiently conscious about contraceptive use, but contraceptive usage was found to be an important factor for HIV/AIDS awareness [15]. Most residents know that HIV/AIDS is a contagious disease, though their participation in HIV workshops is not satisfactory. It is a good sign that most of these respondents have participated in HIV awareness programs organized by their respective garment industry employer. The assistance of other persons, such as, health workers, friends, parents were found to be important predicators for HIV awareness among respondents. This is also consistent with the findings of [13]. Mass media programs (electronic and print media) show positive sign of increasing awareness among all groups consistent with $[13,16]$. This study found that, radio programs and TV programs about HIV/AIDS, are both important predicators in HIV/AIDS awareness as both has positive effects on HIV/AIDS awareness. In this study, participants in HIV/AIDS workshops were more likely to aware compared to those who have not participated in such workshops which indicate the effectiveness of such programs.

\section{Conclusion}

HIV/AIDS awareness has become one of the burning health issues across the world. HIV/AIDS awareness in Bangladesh has long been a topic of interest in research including all sectors of population because it has a direct relationship with the prevalence of HIV. The analyzed results show large proportions of respondents are in very young ages, most of them have secondary education and are unmarried. It also shows that almost all garments workers are aware about HIV/AIDS, though their knowledge regarding prevention is not satisfactory. HIV/ AIDS awareness depends on respondent's education, contraceptive usage, radio programs and TV programs on HIV/AIDS, their participation in HIV/AIDS workshop and the assistance of other persons to make them aware of HIV/AIDS. Though Bangladesh has a low prevalence of HIV, there remain a number of factors that make the country at high risk in acquisition and transmission of HIV. Therefore, it is the time to give more emphasis on education, mass-media exposure, workshops, and campaign.

\section{Acknowledgements}

The authors would like to thank to the Faculty of Science, University of Rajshahi, Bangladesh for the research grant without which this study would not have been possible. Again the authors are also very grateful to the garments workers and to the editor and the referees for their valuable comments and criticism, which led to a much improved version of the paper.

\section{REFERENCES}

[1] Center for Disease Control and Prevention (CDC), "Morbidity and Mortality Weekly Report," Center for Disease Control and Prevention, Vol. 50, No. 21, 2001.

[2] UNAIDS, “World AIDS Day Report,” UNAIDS, 2011.

[3] UNAIDS, "UNAIDS Report on the Global AIDS Epidemic," 2010.

[4] National AIDS/STD Program (NASP), "UNGASS Country Progress Report," National AIDS/STD Program, Ministry of Health \& Family Welfare (MOHFW), Government of Bangladesh, 2010.

[5] UNAIDS, "20 Years of HIV in Bangladesh: Experience and Way Forward," UNAIDS, 2009.

[6] M. M. Islam and K. M. Conigrave, "HIV and Sexual Risk Behaviors among Recognized High-Risk Groups in Bangladesh: Need for a Comprehensive Prevention Program," International Journal of Infectious Diseases IJID Official Publication of the International Society for Infectious Diseases, Vol. 12, No. 4, 2008, pp. 363-370. doi:10.1016/j.ijid.2007.12.002

[7] P. L. Johnson, "Male Migrants as a High-Risk Group: Harm Reduction and HIV/AIDS in Bangladesh," Asian Affairs, Vol. 25, No. 3, 2003, pp. 5-29.

[8] National AIDS/STD Program (NASP), "UNGASS Country Progress Report," National AIDS/STD Program, Ministry of Health \& Family Welfare (MOHFW), Government of Bangladesh, 2011.

[9] World Bank (WB), "HIV/AIDS in Bangladesh," The World Bank, 2009.

[10] A. Barkat, M. Majid, R. Ara, et al., "Study on Change in Attitude and Behavior of Garment Owners, Managers and 
Workers towards Gender and Reproductive Health Issues," Human Development Research Centre, 2008.

[11] Communist Internationalist (CI), "The CIA World Fact Book 2005-2006," US Department of State, Area Handbook of the US Library of Congress, 2006.

[12] M. M. Rahman, M. Kabir and M. Shahidullah, "Adolescent Knowledge and Awareness about AIDS/HIV and Factors Affecting Them in Bangladesh," Journal of Ayub Medical College Abbottabad, Vol. 21, No. 3, 2009, pp. 3-6.

[13] S. Akter and M. Rahman, "Socio-Demographic Covariates Play a Tremendous Role in Mounting HIV/AIDS Awareness, Knowledge among Slum Women in Bangladesh," Revista de Ciências Médicas e Biológicas, Vol. 8,
No. 3, 2009, pp. 250-255.

[14] M. S. Rahman and M. L. Rahman, "Media and Education Play a Tremendous Role in Mounting AIDS Awareness among Married Couples in Bangladesh," AIDS Research and Therapy, Vol. 4, 2007, p. 10. doi:10.1186/1742-6405-4-10

[15] M. N. I. Mondal, M. M. Hossain and M. M. Rahman, "Knowledge and Awareness about HIV/AIDS among Garments Workers in Gazipur District, Bangladesh," The Social Sciences, Vol. 3, No. 7, 2008, pp. 528-530.

[16] M. Rahman, "Determinants of Knowledge and Awareness about AIDS: Urban-Rural Differentials in Bangladesh," Journal of Public Health and Epidemiology, Vol. 1, No. 1, 2009, pp. 14-21. 